\title{
Introducción \\ Especial en derecho privado
}

El derecho privado experimenta profundos cambios debido a los rápidos avances de la tecnología, el surgimiento de novedosos activos intangibles, el uso extendido de mecanismos alternativos de solución de controversias, los reclamos de uniformidad regulatoria realizados por los comerciantes globales, la aparición de formas flexibles de organización empresarial, la constitucionalización y los demás fenómenos asociados a la transformación de las fuentes. Así, este número de la revista se dedica a trabajos que analizan esas transformaciones en el ámbito local y en países como Argentina, Chile y España.

Los retos que plantean las normas de conflicto en el derecho internacional privado son analizados en tres artículos. El primero de ellos se titula "Fuentes del derecho internacional privado en el sistema jurídico argentino: jerarquía normativa y su interpretación jurisprudencial", en el que la autora concluye que las recientes reformas legislativas en Argentina han incorporado un nuevo derecho internacional privado pro homine que ordena a los jueces argentinos la aplicación de instrumentos de derechos humanos al resolver una relación jurídica internacional.

De otra parte, el artículo "Los acuerdos prematrimoniales en derecho internacional privado español" estudia una de las figuras de frecuente utilización en materia internacional: los acuerdos prematrimoniales. La autora explica cómo en la actualidad, debido a la movilidad de las personas, los matrimonios en los que los cónyuges no comparten nacionalidad y que deciden regularse mediante un acuerdo prematrimonial, los efectos de una posible ruptura son contratos de común uso. 
Desde una perspectiva nacional, el artículo "La elección del derecho aplicable en el derecho internacional privado en Colombia" presenta un diagnóstico sobre las normas de conflicto de leyes existentes en el país. Los autores concluyen que la regulación local no responde adecuadamente a las exigencias de las realidades que emergen de hechos y negocios jurídicos contemporáneos.

Ahora bien, en este número de la revista, también se abordan asuntos contractuales contemporáneos. Así, en el artículo "Los contratos normativos y los contratos marco en el derecho privado contemporáneo", la autora presenta un excelente análisis de los elementos fundamentales que nutren los contratos normativos y los contratos marco y analiza las principales problemáticas de estos contratos de frecuente utilización. Por su importancia, estas figuras han sido objeto de diversos análisis que reflejan desacuerdos sobre su concepto, su naturaleza y sus efectos, analizados en el texto.

En materia de mecanismos de solución de controversias de derecho privado, la revista contiene dos interesantes artículos: el texto "Restitución e indemnización a sujetos indeterminados, cy-près y acciones de clase" ofrece, desde una perspectiva histórica y comparativa, un análisis sobre la posibilidad de admitir acciones de clase en favor de sujetos indeterminados. Para ello, los autores acuden a la doctrina del cy-près del common law y muestran su aplicación a las acciones de clase y las objeciones que la utilización de esta teoría ha enfrentado desde las jurisdicciones de derecho civil continental. Así, los autores ofrecen una visión crítica de la reciente introducción de la doctrina del cy-près en jurisdicciones latinoamericanas. Por su parte, el artículo denominado "La arbitrabilidad subjetiva en el contrato de fiducia en Colombia" presenta interesantes reflexiones sobre un tema central en materia de arbitraje: el pacto arbitral. El autor analiza los problemas que surgen para los no signatarios en el contrato de fiducia y analiza algunas hipótesis para demostrar que las figuras que en la actualidad se utilizan para la extensión del pacto arbitral pueden implicar la violación de derechos de terceros.

Este número de la revista también incluye artículos que analizan los retos que impone la tecnología al derecho privado. Un impactante problema es analizado en el texto "Control de nuestros datos personales en la era del big data: el caso del rastreo web de terceros". Allí, la autora presenta las formas en las que la industria de datos recoge información de millones de 
fuentes para perfilar a las personas según sus condiciones demográficas, sus prácticas de consumo, sus intereses políticos. La autora muestra los resultados de una evaluación sobre la efectividad del modelo de consentimiento informado en Colombia y concluye que existe un bajo cumplimiento de los estándares mínimos de información y de libertad necesarios para que las personas controlen el uso de los datos recolectados por medio de tecnologías de rastreo.

En la misma línea temática, el artículo "Tecnología, relaciones laborales y derecho del trabajo: acerca de la tensión entre la técnica y la persona" presenta las divergencias entre las nociones de técnica y persona en el derecho laboral. En particular, el autor reflexiona sobre el modo en que el cambio tecnológico afecta el lugar privilegiado asignado normativamente al sujeto más débil de una relación productiva. El texto identifica algunas respuestas institucionales y judiciales ofrecidas en el ámbito internacional y concluye identificando la necesidad de actualizar las herramientas interpretativas del derecho del trabajo con el fin de mantener su función compensadora en el marco del progreso técnico.

JUAN PABLO CÁRDENAS

YIRA LÓPEZ

Editores invitados 